\title{
UMA ODISSÉIA PELOS DOCUMENTOS : LEITURAS DO LIVRO "ANTIGÜIDADE CLÁSSICA: A HISTÓRIA E A CULTURA A PARTIR DOS DOCUMENTOS"
}

\section{Renilson Rosa Ribeiro}

\section{Resumo}

O presente artigo pretende realizar uma reflexão sobre o livro Antigüidade Clássica: A história e a cultura a partir dos documentos, de Pedro Paulo Abreu Funari, professor de História Antiga e Arqueologia Histórica (Universidade Estadual de Campinas) a luz de suas proposições metodológicas e temáticas para o ensino de História Antiga nas universidades e escolas de educação básica no Brasil.

Palavras-chave

Mundo Antigo; História; Documentos; Metodologia; Ensino

\section{AN ODYSSEY BY THE DOCUMENTS: READINGS OF THE BOOK ANTIGÜIDADE CLÁSSICA: A HISTÓRIA E A CULTURA A PARTIR DOS DOCUMENTOS}

\begin{abstract}
This article intends to realize an analyze about Antigüidade Clássica: A história e a cultura a partir dos documentos, published by Pedro Paulo Abreu Funari, professor of Antique History and Historical Archaeology (Campinas State University), giving special attention to his methodological and theoretical proposals for the studying and teaching of Antique History in Brazilian universities and secondary schools.
\end{abstract}

\section{Keywords}

Ancient World; History; Documents; Methodology; Teaching 


\section{INTRODUÇÃO}

Publicado originalmente em 1995 pela Editora da UNICAMP, Antigüidade Clássica: A história e a cultura a partir dos documentos, de autoria do historiador e arqueólogo Pedro Paulo A. Funari, docente do Departamento de História da Universidade Estadual de Campinas (UNICAMP), apresenta-se com um livro-texto destinado a estudantes de graduação dos cursos superiores de ciências humanas, podendo ser adotado como material de apoio e atividades, por professores do ensino fundamental e médio e pelo público em geral interessado sobre o tema. A relevância das propostas presentes neste livro pode ser evidenciada pela sua recente reedição no ano de 2003 pela Editora da UNICAMP e também pela sua indicação como obra de referência para a área de História em concursos públicos como, por exemplo, o Concurso Público para Provimento de Cargos de Professor de Educação Básica II, realizado em novembro de 2003, pela Secretaria de Estado da Educação de São Paulo.

De acordo com o autor,

esta coletânea de documentos sobre a Antigüidade Clássica responde a uma demanda, há muito sentida em nosso meio, de um livro que apresentasse um conjunto significativo de fontes antigas, não apenas escritas como materiais e artísticas. Os documentos escritos foram, em geral, traduzidos das línguas originais; em alguns casos específicos, utilizaram-se versões já existentes em português, em particular as transcrições poéticas. Procurou-se diversificar, ao máximo, as categorias documentais e os temas abrangidos, visando introduzir o leitor à grande variedade de abordagens do mundo antigo. (FUNARI, 2003, p. 11).

Escrito de forma didática e estrutura dos capítulos bem definida e coerente com a proposta de trabalho de Funari, este livro-texto traz significativas contribuições para os estudos sobre o tema no Brasil. Esta obra é fruto de um engajamento do autor, através de livros e artigos em revistas especializadas reconhecidas nacional e internacionalmente para o enriquecimento do saber histórico na sala de aula e, conseqüentemente, sua renovação. Notamos uma preocupação, numa proposta prática e arrojada como esta, com a formação intelectual e cultural de nossos estudantes nos três níveis de ensino. Este livro nasceu a partir das experiências e diálogos realizados pelo autor com os alunos de graduação nos cursos de História Antiga e especialistas no assunto.

(C) ETD - Educação Temática Digital, Campinas, SP, v.5, n.2, p.75-86 , jun. 2004 - ISSN: 1517-2539. 
O livro inicia-se com dois dos seus dez capítulos sobre análise documental, seus fundamentos e características. Podemos dizer que esta primeira parte (Capítulos I e II) do livro é essencial para conhecer as estratégias de estudo da história da Antigüidade Clássica traçadas por Funari com base numa fundamentação teórica bem detalhada e de fácil compreensão do leitor. Dedicaremos especial atenção na leitura destes dois capítulos em nossos comentários sobre este livro por esta razão. Os outros capítulos recolhem documentos, divididos por eixos-temáticos, e comentados de forma mais ou menos aprofundada. Os eixos-temáticos escolhidos pelo autor a serem tratados no livro são: Memórias (Capítulo III); Práticas (Capítulo IV); Sentimentos (Capítulo V); Reflexões (Capítulo VI); Expressões (Capítulo VII); Poderes (Capítulo VIII); Espaços (Capítulo IX) e Experimentos (Capítulo X). Todos os capítulos são finalizados por atividades resolvidas e a serem resolvidas por professores e alunos em sala de aula. Estas questões, de acordo com o autor, têm diferentes níveis de complexidade, o que permite ao leitor familiarizarse com o universo dos documentos antigos. Devemos ressaltar que Funari traz no final do livro um pequeno vocabulário de expressões clássicas mais usuais para instrumentalizar os leitores com termos fundamentais para os estudos clássicos. As obras citadas, ao longo da obra, são listadas em ordem alfabética.

A organização deste livro em capítulos temáticos permite a realização, por exemplo, nos cursos superiores, de seminários pelos alunos. Talvez resida neste aspecto aberto a novas formas de ensino-aprendizagem o êxito deste livro-texto. Ele pode ser um excelente ponto de partida para despertar o interesse dos estudantes para o mundo da pesquisa científica. Para os professores do ensino fundamental e médio, o livro representa uma fonte inesgotável de textos escritos e nãoescritos a serem utilizados nas aulas de História.

Feita as devidas apresentações, vamos agora nos debruçar um pouco sobre os dois capítulos teóricos e metodológicos que abrem este livro.

No Capítulo I - Documentos: análise tradicional e hermenêutica contemporânea, Funari realiza uma apresentação das principais questões subjacentes aos documentos, sua análise e as premissas básicas que regeram a seleção dos eixos-temáticos abordados. 
Antes de adentrar no capítulo em questão, o autor reafirma em nota introdutória o compromisso do seu livro com o seu público e com uma educação interdisciplinar:

O público a que se destina esta obra não se restringe aos graduandos em História, mas engloba professores universitários e alunos de História, Letras, Ciências Sociais, Filosofia, Política, Arqueologia, assim como professores de primeiro e segundo graus e todos os interessados em geral. Henri Irénee Marrou (1965, p.1538) ressaltava que "seria necessário, também, escrever livros de boa vulgarização, verídicos, mas que estejam ao alcance do homem comum, para alimentar a cultura geral sob a forma mais ampla”.

Pretende-se, portanto, que o público deste livro seja bastante amplo e heterogêneo. Isso significa que os níveis de análise e interpretação dos documentos selecionados deverão, necessariamente, adequar-se aos diferentes leitores. (FUNARI, 2003, p. 14).

O que podemos perceber nesta citação é a crítica do autor a uma leitura unívoca e fechada dos documentos selecionados. Esta orientação estará presente em vários momentos da obra.

Neste capítulo, Funari (2003, p. 15) faz uma leitura das concepções tradicionais do que se concebe como documento histórico e a sua leitura. Vejamos o que ele comenta sobre a análise tradicional do documento:

O documento foi definido tradicionalmente como um texto escrito à disposição do historiador. Fustel de Coulanges $(1888,29 ; 33)$ afirmava que "a habilidade do historiador consiste em retirar dos documentos o que contém e nada acrescentar... A leitura dos documentos de nada serviria se fosse feita com idéias preconcebidas”. A partir deste pressuposto, dois procedimentos básicos deveriam ser adotados, denominados, convencionalmente, de crítica externa e crítica interna. A busca da veracidade do relato, implícita nesta abordagem deveria ser levado a cabo, em primeiro lugar, por um estudo dos aspectos externos do documento. A materialidade do texto deveria ser questionada e posta à prova: haveria incompatibilidade entre a data escrita no texto e sal composição física? (...)

Um texto escrito apresenta, também, uma série de informações que podem ajudar a caracterizar o documento como verdadeiro ou falso. A crítica interna visa verificar se há motivos para duvidar da sua autenticidade devido a informações inverossímeis. Um tipo de inverossimilhança muito comum é o anacronismo”.

Nesta perspectiva, somente um conhecimento apurado e aprofundado das condições materiais e históricas de inserção do documento permitiria levar a cabo as críticas externa e interna. O conhecimento da erudição filológica torna-se indispensável para esta tarefa:

De fato, apenas o conhecimento aprofundado da linguagem utilizada nos documentos permite a execução de uma sólida crítica interna. (...) Apenas uma grande erudição, um domínio exaustivo das línguas grega e latina, permite julgar se termos específicos deveri- 
am ser considerados verdadeiros ou espúrios. O uso de termos anacrônicos permite questionar a veracidade das afirmações de um documento. (FUNARI, 2003, p. 16).

De acordo com Funari, a moderna ciência histórica, alicerçada na crítica factual do documento escrito, surgiu como resultado da atuação de classicistas e estabeleceu os parâmetros da análise textual chamada de tradicional.

Em seguida esta breve referência à análise tradicional do documento, o autor discute a relação passado e presente na História e as contribuições da hermenêutica contemporânea. A disciplina histórica continua sendo pautada pelo conhecimento através dos documentos, contudo redefiniram-se os conceitos de história e de documentos. Para Funari (2003, p. 17), amparado nas afirmações de Laurent Stern, os eventos passados, de acordo com a boa intuição, não podem mudar, mas nossa interpretação destes eventos muda. Dessa maneira:

De fato, não se deve confundir passado e relato do passado, acontecimentos objetivos intangíveis e a narrativa histórica. O pensador francês Raymond Aron (s/d: 11) ressaltava que "a mesma palavra refere-se à realidade histórica e ao conhecimento dela derivado. História designa, a um só tempo, o passado e a ciência que os homens esforçam-se em elaborar a partir desse passado.”

A partir da referência de autores clássicos com Tito Lívio, o autor nos fala da impossibilidade e irrelevância de descrever o passado tal qual teria ocorrido. Eis a justificativa apresentada para esta afirmação que deixaria os defensores devotos do positivismo arrepiados:

Impossível, na medida em que não se possuem senão fragmentos mínimos do passado mas, impossível também, porque tudo descrever, ainda que fosse factível, acabaria por nada explicar, esvaziando de sentido o relato. Irrelevante, pois o presente só se interessa pelo passado em função de si próprio e do futuro. (...) A subjetividade subjacente a toda compreensão histórica, explicitada tantas vezes pelos pensadores antigos, tem sido ressaltada pelo moderno pensamento histórico (Fox 1993:47). Na verdade, já o poeta alemão Goethe reconhecia que "toda ação é, imediatamente, teoria”, todos os atos, inclusive os relatos, são resultados de modelos de interpretação (MAIER, 1984 apud FUNARI, 2003, p. 18).

Neste momento do capítulo, Funari (2003, p. 18) nos mostra que a própria razão, ou seja, a maneira de compreender e interpretar a sociedade e o mundo, seja esteticamente, seja nas transformações, é historicamente determinada. A relatividade do discurso histórico, desta forma, vem questionar e desmantelar a oposição entre fatos e interpretações, na base do positivismo oitocentista em busca das “evidências”: 
Evidências, nada evidentes no sentido corriqueiro da palavra, não podem fundar as interpretações, mas, ao contrário, são estas que criam as evidências e os fatos (SOMEKAWA ; SMITH 1988, p.105). A oposição entre fatos e teorias mostra-se, nesta perspectiva, artificial e enganosa (TABACZYNSKY, 1984, p.21). Até mesmo a diferença entre história e mito tem sido posta em questão.

No que concerne à subjetividade presente no fazer histórico, o autor coloca o historiador na sua condição humana, não mais como um ser sobrenatural, uma divindade acima do bem e do mal. A aceitação da subjetividade da História, na leitura de Funari, está ligada a dois processos da vida intelectual do século passado (XX):

Em primeiro lugar, ao influxo da Filosofia deve ser creditada a difusão da própria noção de subjetividade. Todo conhecimento, não apenas, nem especificamente, o conhecimento do passado, mas toda a compreensão (verstehen) resulta de sujeitos do conhecimento. (...)

Paralelamente à filosofia, a lingüística e a semiótica viriam influenciar, decisivamente, o estudo de todas as ciências, em particular as humanas. A noção de que todo conhecimento expressa-se, necessariamente, como um discurso implicou o reconhecimento da importância de sua autoria e de seu público, assim como da forma e conteúdo desse discurso. A aceitação da noção de subjetividade, Poe si mesma, não responde à questão central: por que diferentes historiadores têm diferentes pontos de vista? A autoria do discurso histórico, entretanto, significa que o produtor do texto, a partir dos seus interesses individuais e coletivos, visa fazer crescer, no seu público, sentimentos e sensações: auctor, o autor, nada mais é do que aquele que faz crescer (augere). (FUNARI, 2003: p. 19).

Nesse cenário, a narrativa, o relato como construção discursiva, ocupa um lugar de destaque nas reflexões elaboradas pela historiografia contemporânea. A importância da narrativa da História, nesta esfera, ultrapassa os limites da constatação da estrutura lógica da narrativa e atinge a própria definição ontológica da disciplina. Segundo Funari (2003, p. 20),

A narrativa histórica requer, portanto, habilidade de exposição, explicação e persuasão através do uso das palavras (ELTON 1967, p.106). Tradicionalmente, a oposição entre estória (res fictae) e História (res factae) permitia separar a literatura ficcional da História (MOMMSEN 1984, p.68). Mas ciência e arte, outrora tão opostas, constituem, nas ciências humanas contemporâneas, aspectos interligados do discurso (STRASBURGER 1966, p.55). (...) Esta aproximação entre a ficção e a História deriva, justamente, da dificuldade de distinguir, enquanto construções discursivas, relatos históricos e ficcionais (WHITE 1976:22). Há quem não hesite em renomear a História: estória (story, Elton 1970:22), antes de mais nada um gênero literário (un genre littéraire par excellence, Cizek 1991:136).

Não seria o caso de dissolver, completamente, as diferenças entre a ficção e a ciência, pois o discurso científico tem, sempre, que manter uma reflexão entre sua criação estética e os 
documentos. (...) No entanto, o caráter poético, estilístico e retórico do discurso científico constitui em elemento central na hermenêutica contemporânea. As palavras escolhidas, a maneira de apresenta-las, a estrutura estética da argumentação formam o núcleo de qualquer discurso.

Para o autor, na conclusão deste capítulo, todo discurso pretende ser uma descrição da realidade. E “análise do discurso permite justamente, estudar qualquer documento como construção complexa, estruturada, com autoria, públicos e objetivos específicos. Esta, talvez, a maior aquisição da moderna semiótica para o estudo da História.” (FUNARI, 2003, p. 22).

Comprometido com a seriedade do trabalho do historiador, Funari (2003, p. 22) não ilude o seu leitor e afirma categoricamente que a análise do discurso histórico não é uma tarefa simples. E faz as seguintes observações, que devem ser anotadas no caderno de pesquisa de qualquer profissional que se debruce sobre este tipo de atividade (creio que este conselho sirva para qualquer profissional do saber científico):

A interpenetração entre interpretação e os acontecimentos objetivos impossibilita a execução de uma descrição dos fatos. (...) Os acontecimentos, as mortes e as alterações políticas, descritos nos documentos, só são inteligíveis em um discurso lógico, com uma seqüência de argumentos. Separar "fatos” de interpretações torna-se uma tarefa inútil. Ao contrário, o estudo dos relatos como construções discursivas permite uma visão crítica dos motivos e objetivos subjacentes a todos os discursos “.

O Capítulo II - Análise documental e Antigüidade Clássica, abre com uma discussão sobre os documentos e a sua seleção e, depois, parte para uma explicação sobre análise documental e sua diversidade e sobre as especificidades do estudo da Antigüidade Clássica. O capítulo se encerra com uma pequena reflexão sobre as periodizações tradicionais da história, literatura e cultura clássicas. Na mesma linha do capítulo anterior, Funari não foge ao seu estilo objetivo e claro no trato do tema com o leitor. Devemos notar a capacidade de síntese do autor ao apresentar em poucas páginas um manancial rico de informações sem ser superficial ou vazio.

A tradição historiográfica considerava como documento histórico textos escritos. Hoje, costuma-se ignorar toda a produção literária não-clássica. Isso exclui a maior parte da história da cultura. Contra esta tendência o autor fará sua seleção de fontes utilizando-se dos mais variados tipos de documentos para a obtenção de informações sobre o tema para os mais variados tipos de leitores que possam perambular pelas páginas do livro. 
Nas suas palavras, a seleção das fontes para os demais capítulos

procurou abranger um grande espectro de temas, de tipos diversos de documentos, analisados a partir das diferentes ciências humanas. Se descuidar do erudito e do grandioso, incluíram-se o corriqueiro e o comenzinho (the recovery of the everyday or the mundane, nas palavras de GIDDENS, 1987, p.4). (...)

Os documentos procuram abranger diferentes categorias documentais: textos transmitidos pela tradição textual, epígrafes, restos arqueológicos. Diversas, também, as abordagens: textos filosóficos, poesias, documentos oficiais, leis. Isso permitirá ao leitor familiarizarse com a variedade de documentos disponíveis e com as diferenças de análise que cada categoria documental impõe aos pesquisadores. (FUNARI, 2003, p. 26-7).

Quanto à análise documental, o autor anuncia de imediato que os documentos podem ser analisados de múltiplas maneiras tendo em vista, em especial, o interesse e curiosidade sobre o tema, os níveis de profundidade do estudo, as diferentes áreas de saber e os diferentes paradigmas ou modelos hermenêuticos.

De acordo com Funari (2003, p. 27), existem muitos modelos de análise documental, o que cria possibilidades infinitas de olhares. Em linhas gerais, ele aponta alguns procedimentos ressaltados por diferentes autores, em particular em manuais de amplo uso, no trato com fontes documentais; "leituras sucessivas do texto devem ser seguidas pela constituição de uma bibliografia prática e precisa. Cada parágrafo deve ser resumido no seu conteúdo substancial. O comentário deve incluir detalhes sobre o autor e as circunstâncias históricas”.

Ele destaca ainda que outros autores propõem um roteiro mais detalhado de análise:

1. Aspectos externos, com estudo da tipologia de fontes (textos de ficção, legislação, epistolar etc.), lugar de origem e datação do texto, estilo e características lingüísticas; 2. Resumo, consistindo em uma sinopse do texto; 3 . Contexto histórico, inserindo o texto em quadros cronológicos, geográficos e temáticos (e.g. economia, cultura, política, guerra) específicos; 4. Explicação detalhada do documento, envolvendo um estudo minucioso dos termos utilizados em seu contexto; 5. Autoria, inserindo o autor nas circunstâncias historiográficas sobre o tema e o período; 7. Bibliografia consultada" (FUNARI, 2003, p. 27-8).

Ainda no campo da análise documental, o autor destaca outras possibilidades adotadas por outros especialistas como a crítica textual, em especial, a crítica filológica textual. 
Como o livro-texto introduz no seu corpo de documentos outros tipos de fontes além das escritas, Funari traça algumas considerações sobre a necessidade de outros critérios específicos no trato com estes outros tipos de fonte (por exemplo, vestígios materiais e artes).

Mas antes de adentrar por este terreno, ele registra algumas informações relevantes de caráter geral, aplicáveis a todos os tipos documentais, e que poderão ser de extrema importância para nortear os comentários realizados, em diferentes níveis, pelo autor nessa coletânea.

Em primeiro lugar, consideram-se todos os documentos, escritos ou não, como discursos. Enquanto discursos possuem, necessariamente, autoria e público e, como todo discurso, têm estruturas superficiais e profundas. A autoria pode ser individual ou coletiva, material ou intelectual. (...) O público pode ser individual ou coletivo, homogêneo ou heterogêneo.

A estrutura de superfície de um discurso corresponde à sua seqüência explícita de elementos constitutivos. Parágrafos sucessivos de um texto apresentam idéias concatenadas, enquanto um edifício apresenta uma planta, funcionalmente ordenada, de seus aposentos. Esses são os aspectos visíveis da organização de um discurso. Sua estrutura profunda, de acesso indireto, mediado pelo raciocínio do próprio observador, liga-se aos interesses e objetivos do autor e do público. A reconstrução desses interesses, inevitavelmente subjetiva, variará segundo os pontos de vista, interesses e conhecimentos do próprio analista. (FUNARI, 2003, p. 28-9).

Já para um objeto arqueológico, o autor propõe uma exegese própria:

Em particular, o estudo pormenorizado da constituição material do artefato implica a análise da composição física: cerâmica, vidro, madeira etc. a estrutura superficial do artefato, sua constituição como objeto arqueológico, impõe uma análise da sua funcionalidade. Assim, uma casa possui aposentos que se articulam, explicitamente, de maneira funcional. Essas funções, contudo, encobrem uma estrutura profunda, os objetivos apenas implícitos nas funções: a existência de aposentos para os escravos, por exemplo, e sua exata localização em uma habitação específica revelam intenções dos construtores (isolamento, controle do movimento etc.). O público, ou seja, o consumidor ou usuário, de um artefato material também deve ser estudado: um anel de ouro destinava-se a certos grupos abastados, enquanto uma ânfora de vinho barato era consumida por extratos sociais mais amplos. (FUNARI, 2003, p. 29-30).

Feitas as devidas considerações sobre a proposta analítica, Funari (2003, p. 30) explica a maneira como foi feita a organização dos documentos ao longo dos capítulos temáticos. Em primeiro lugar, as diversas categorias documentais que foram comentadas ao longo do livro representam uma enorme variedade de discursos. E dentre os textos escritos selecionados, alguns fo 
ram apresentados na versão original, permitindo ao leitor fazer uma análise filológica aprofundada. No entanto, o restante foi apresentado somente na forma de traduções e os comentários referentes a estes documentos "restringir-se-ão à versão, em vernáculo, apresentada. A maior parte dos textos foi traduzida pelo organizador desta obra, mas algumas versões de autoria alheia foram introduzidas, em particular, quando uma recriação poética, em português, já foi publicada”.

Para os documentos materiais - artefatos e pinturas, o autor explica que estes foram:

apresentados pela primeira vez e os comentários mesclam análises publicadas, em línguas estrangeiras e em obras especializadas de difícil acesso, com interpretação do organizador desta coletânea. Aos documentos comentados seguem-se diversos outros a serem utilizados pelos leitores, completados por exercícios de análise resolvidos e a resolver” (FUNARI, 2003: p. 30).

Ao tratar das especificidades do estudo da Antigüidade Clássica, Funari (2003: p. 30) comenta que os estudiosos desta área têm sido considerados pouco propensos à interpretação, voltados, muitas vezes, para uma erudição estéril e conservadora: “Não há dúvida de que o racismo (HALEY, 1993), o machismo (RABINOWITZ ; RICHLIN, 1993) e até mesmo o fascismo aberto têm caracterizado uma parcela dos estudos clássicos.

Contudo, o estudo desta temática não precisa necessariamente reforçar preconceitos nem se constituir em elemento de opressão, mas, para tal mudança de atitude, faz-se necessário dominar o rigor e erudição. Com esta preocupação em mente, o livro parte de diversos pressupostos:

o domínio da cultura clássica tem como principal objetivo "promover uma reflexão constante sobre as condições humanas e sociais que conduza à crítica social contemporânea” (NORDBLANCH, 1989, p.133). Se não é possível encarar o passado e o presente sine ira et studio, sem engajamento (HOLZER, 1985, p.23), a superação da História "como instrumento de poder dos vencedores”, nas palavras de Edgar De Decca (1992, p.133), depende, em primeiro lugar, do conhecimento aprofundado da Antigüidade. Apenas o conhecimento de primeira mão fundamenta a visão crítica e, nesse sentido, a leitura de Aristóteles, assim como de outros autores clássicos, permanece indispensável para pensarse tanto o mundo antigo como o contemporâneo (GIANOTTI, 1994, p.13 apud FUNARI, 2003, p. 31).

Além disso, Funari (2003, p. 31) propõe a necessidade de se ampliar o universo de temas e abordagens da Antigüidade. Devem ser colocados em cena os camponeses e as mulheres, a fa 
mília e os rituais, os gestos e os monumentos, a dominação e a resistência: "Esses e outros temas devem ser apresentados no contexto de uma pluralidade de interpretações (Ankersmit 1986:26) e um dos critérios aqui utilizados para a seleção da documentação consistiu, precisamente, no potencial de proposição de diferentes abordagens e significados”.

Quanto à periodização, o autor as enxerga como divisões artificiais, uma vez que diferentes pontos de vista, fundadas em diversas metodologias, disciplinas acadêmicas e concepções de mundo, resultam em divisões alternativas. A finalidade, na sua leitura, da apresentação das periodizações usuais resume-se à instrumentalização dos leitores e não implica necessariamente a aceitação dos seus pressupostos. Dessa maneira,

O próprio uso do termo Antigüidade Clássica, no título deste livro, resulta de um compromisso: convencionalmente, as civilizações grega e romana da Antigüidade são chamadas “clássicas". O termo, quando se refere a essas duas culturas antigas, possui, contudo, conotações ambíguas ao considerar essa Antigüidade como um modelo - o clássico a ser imitado pelos modernos - e ao restringir sua abrangência aos homens cultos da elite, por oposição às mulheres, aos “incultos” e aos pobres (BROWN, 1993, p.247 et passim). O uso do termo Antigüidade Clássica, neste livro, não implica, contudo, a aceitação dessas conotações e é usado para designar a cultura greco-romana nas suas mais variadas manifestações. (FUNARI, 2003: p. 33).

Para finalizar este capítulo, Funari alerta que não é recomendável encarar as periodizações senão como “instrumentos analíticos” que são úteis para o saber.

Feitas estas considerações iniciais, o autor nos convida a uma odisséia pela história e a cultura da Antigüidade Clássica através dos documentos criteriosamente selecionados e organizados dentro de temas como memórias, práticas, sentimentos, reflexões, expressões, poderes, espaços e experimentos. E como Ulisses, personagem homérico, os leitores - viajantes, como diria Braudel - desvendam este mundo fascinante e fantástico. Um mundo que se renova e ganha novas tonalidades a cada viagem que se inicia ao folhear as páginas deste livro. Pois, como nos lembra Certeau, no livro A Invenção do Cotidiano - Artes de fazer ,

Longe de serem escritores, fundadores de um lugar próprio, herdeiros dos lavradores de antanho - mas, sobre o solo da linguagem, cavadores de poços e construtores de casas -, os leitores são viajantes: eles circulam sobre as terras de outrem, caçam, furtivamente, como nômades através de campos que não escreveram, arrebatam os bens do Egito para 
com eles se regalar. A escrita acumula, estoca, resiste ao tempo pelo estabelecimento de um lugar, e multiplica a sua produção pelo expansionismo da reprodução. A leitura não se protege contra o desgaste do tempo (nós nos esquecemos e nós a esquecemos); ela pouco ou nada conserva de suas aquisições, e cada lugar por onde ela passa é a repetição do paraíso. (1994, p.269-270).

\section{REFERÊNCIAS}

CERTEAU, Michel de. A invenção do cotidiano: artes de fazer. Petrópolis, RJ: Vozes, 1994, $351 \mathrm{p}$.

FUNARI, Pedro Paulo. Antigüidade clássica: a história e a cultura a partir dos documentos. 2. ed. Campinas, SP: Ed.UNICAMP, 2003, 155 p.

\section{Agradecimentos}

Agradeço as leituras e sugestões apresentadas para este artigo feitas por Marili Bassini, Mairon Escorsi Valério e Leila Massarão, amigos e pesquisadores da Pós-IFCH/UNICAMP. Aos professores de História dos cursos preparatórios para o PEBII - 2003 das cidades de Indaiatuba e Mogi-Mirim, que debateram e comentaram conosco o livro analisado neste artigo. Devo ressaltar, no entanto, que possíveis incoerências presentes no texto são de inteira responsabilidade de seu autor.

RENILSON ROSA RIBEIRO

Bacharel e licenciado em História (UNICAMP) Atualmente desenvolve pesquisa de Mestrado em História Cultural no Programa de Pós-Graduação do Instituto de Filosofia e Ciências Humanas/UNICAMP

sob a orientação do Prof. Dr. Paulo Celso Miceli. e-mail: Hrenilson@unicamp.brH I Hrrrenilson@yahoo.comH

Recebido em: 15/05/2004

Aceito em: 26/07/2004 